Borneo Journal of Sciences and Technology, Volume (2), Issue (1), Pages: 63-69

DOI: https://doi.org/10.35370/bjost.2020.2.1-11

e-ISSN: 2672-7439

(C) 2018, UCTS Publisher.

Submitted: $5^{\text {th }}$ November 2019

Accepted: $10^{\text {th }}$ December 2019

Published: $31^{\text {th }}$ January 2020

\title{
Utilization of Hydroxyapatite from Shortfin Scad (Decapterus macrosoma) Bones as Calcium Fortificant in Cookies
}

\author{
Mohd Syafiq Abdullah, Derick Tsai Kien Cheng and Abdul Fattah Ab Razak \\ School of Engineering and Technology, University College of Technology Sarawak, 96000 Sibu, \\ Sarawak, Malaysia
}

\begin{abstract}
Shortfin scad (Decapterus macrosoma) is locally known as selayang, basung and sardine in Malaysia. It is commonly used to make ' keropok lekor ' and fish crackers as the main ingredient. The fish's entire body of rounded flesh is considered the main product while head, backbone, trimmings (cutoffs), skin and guts constitute byproducts or wastage. Therefore, in order to leverage the potential of its by-products, the present study is aimed to utilize hydroxyapatite extracted from Decapterus macrosoma bones as calcium fortificant in cookies. In cookies formulation, wheat flour was replaced with hydroxyapatite at $0 \%, 6 \%, 12 \% 18 \%$ and $24 \%$ level. $\mathrm{T}_{24}$ which was incorporated with $9.5 \%$ hydroxyapatite, has demonstrated the highest hardness (3096 g) and calcium content $6.67 \%$ $(\mathrm{w} / \mathrm{w})$, and appeared darkest in color with $\mathrm{L}^{*}, 47.85$. As for sensory evaluation, control sample was preferred by panelists for all sensory attributes evaluated.
\end{abstract}

Keywords: Cookies, Hydroxyapatite, Calcium, Fortification

\section{INTRODUCTION}

Cookies can be savoured as a snack. Having a broad range of selections, longer shelf life and low cost make cookies convenient for consumer [1]. Due to the variety in taste, crispiness and digestibility, cookies hold a significant position in snack foods [2].

Accordingly, the wholesomeness of cookies relies on their ingredients [3]. There have been numerous attempts to enhance cookies ' nutritional benefits by altering their composition. Many food products have been developed through fortification in recent years as consumers are requesting safe, sensory quality foods. Fortifying calcium in cookies, for example, by adding sesame and dried moringa leaves [4].

In line with recent research trends which focuses on sustainable and renewable materials, present study will utilize hydroxyapatite (HAp) extracted from Decapterus macrosoma bones as calcium fortificant in cookies. Shortfin scad (Decapterus macrosoma) from the Carangidae family are readily discovered in Malaysia and are locally known as selayang, basung and sardine [5]. Regardless of being able to be transformed into other low-value products (e.g. fish meal, natural fertilisers), fish bone is underutilized and more commonly being disposed back into the river or sea. Moreover, discarding fish bone into the river indicates poor waste management that might lead to environmental pollution.
To date, no study has been conducted on the use of waste-based HAp in food use. The results of this project will therefore be enriching and beneficial in order to intensify the use of fish waste for global sustainability. This work is therefore aimed at developing calciumfortified cookies through the use of HAp derived from Decapterus macrosoma bones and exploring their physicochemical and sensory properties.

\section{MATERIALS AND METHODS}

The ingredients needed for making cookies such as wheat flour, butter, castor sugar, eggs, vanilla, baking powder and salt were purchased from local market in Sibu, Sarawak. Analytical grades were used in all chemical reagents.

\section{Extraction of Hydroxyapatite from Decapterus macrosoma Bones}

About $10 \mathrm{~kg}$ of Decapterus macrosoma bones were obtained from Terengganu. The bones were transferred to container and boiled for 2 hours in $100{ }^{\circ} \mathrm{C}$. The visible impurities and adherent tissues such as fats flesh and scales were removed through tap water prior being transferred to trays and dried in the furnace at $100{ }^{\circ} \mathrm{C}$ for 24 hours. The dried fish bones were properly packed and sealed in 150 x $90 \mathrm{~mm}$ snap-lock bags (GLAD,

Corresponding Author: Mohd Syafiq Abdullah. School of Engineering and Technology, University of College Technology

Sarawak, mohdshafiq@ucts.edu.my 
Oneplastic, Malaysia) prior to storage at $10{ }^{\circ} \mathrm{C}$ until further use.

The extraction of HAp from the prepared fish bones started off by washing them in tap water, treated with $0.8 \mathrm{M} \mathrm{NaCl}$, followed by soaking in $0.2 \mathrm{M} \mathrm{NaOH}$ for five hours at $5{ }^{\circ} \mathrm{C}$, rinsed again in tap water. Subsequently, the treated bones were dried in drying oven at $60{ }^{\circ} \mathrm{C}$ overnight. The dried bones were calcined at $900{ }^{\circ} \mathrm{C}$ for 3 hours in muffle furnace. The samples were maintained cool naturally in muffle furnace. The calcined bones or known as HAp were ground into powder form by using electric blender (Waring SS-110, Japan). HAp were then sieved to using $100 \mu \mathrm{m}$ sieve. The ground HAp was then stored in closed container for future use.

\section{Cookies Preparation}

Cookies were prepared by adapting formulation from Quiñones, [6]. The basic formulation employed for cookies was $39.5 \%$ wheat flour, $24.6 \%$ butter, $22.0 \%$ castor sugar, $12.0 \%$ eggs, $1.1 \%$ vanilla and $0.2 \%$ salt as shown in Table 1. The substitution of wheat flour was performed at $6 \%, 12 \% 18 \%$ and $24 \%$ level with hydroxyapatite. Based on preliminary study done, the substitution of wheat flour above $24 \%$ level yielded hard texture cookies due to nature of hydroxyapatite which is chemically alike to the mineral component of bones and hard tissues in mammals [7]. slowly introduced and stirred until a velvety dough was achieved. The dough then allowed to rest for 20 minutes and then rolled with a rolling pin to achieve, by visual estimation a uniform thickness of about $1 \mathrm{~cm}$.

Using a $6 \mathrm{~cm}$ diameter cup, the sheeted dough was then cut into circles and baked for $15 \mathrm{~min}$ on nongreased aluminum trays at $170{ }^{\circ} \mathrm{C}$ in gas oven equipped with air-circulating fan. All the cookies from each dough were simultaneously baked on different trays. After baking, cookies were left to cool at room temperature (around $24-26^{\circ} \mathrm{C}$ ) for $25 \mathrm{~min}$ on a cooling rack and then packed in polyethylene bags and kept at room temperature for 3 days in a dry place before chemical and sensory evaluation was conducted.

\section{Color Analysis}

Cookie color measurement was performed using an optical sensor colorimeter based on $\operatorname{CIE~L~} *, a *, b *$ color scheme. $\mathrm{L} *$ values are black to white $(0-100), \mathrm{a} *$ values are positive for redness, and $\mathrm{b} *$ values are positive for yellowness.

\section{Texture Analysis}

Textural analysis was carried out using TA.XT2i SMS Stable Micro Systems Texture Analyzer (Stable Microsystems Ltd., Surrey, England) and adapted the procedure from Budžaki et al., [9]. The three-point

Table 1: Cookies Formulations

\begin{tabular}{cccccc}
\hline \multirow{2}{*}{ Ingredients } & \multicolumn{5}{c}{ Formulation } \\
\cline { 2 - 6 } & $\mathrm{T}_{0}$ & $\mathrm{~T}_{6}$ & $\mathrm{~T}_{12}$ & $\mathrm{~T}_{18}$ & $\mathrm{~T}_{24}$ \\
\hline Wheat flour & $39.5 \%$ & $37.1 \%$ & $34.8 \%$ & $32.4 \%$ & $30.0 \%$ \\
Hydroxyapatite & $0.0 \%$ & $2.4 \%$ & $4.7 \%$ & $7.1 \%$ & $9.5 \%$ \\
Butter & $24.6 \%$ & $24.6 \%$ & $24.6 \%$ & $24.6 \%$ & $24.6 \%$ \\
Castor Sugar & $22.0 \%$ & $22.0 \%$ & $22.0 \%$ & $22.0 \%$ & $22.0 \%$ \\
Eggs & $12.0 \%$ & $12.0 \%$ & $12.0 \%$ & $12.0 \%$ & $12.0 \%$ \\
Vanilla & $1.1 \%$ & $1.1 \%$ & $1.1 \%$ & $1.1 \%$ & $1.1 \%$ \\
Salt & $0.2 \%$ & $0.2 \%$ & $0.2 \%$ & $0.2 \%$ & $0.2 \%$ \\
Baking powder & $0.6 \%$ & $0.6 \%$ & $0.6 \%$ & $0.6 \%$ & $0.6 \%$
\end{tabular}

$* \mathrm{~T}_{0}$ - Control, cookies without wheat flour substitution; $\mathrm{T}_{6}$ - Cookies with $6 \%$ wheat flour substitution; $\mathrm{T}_{12}$ - Cookies with $12 \%$ wheat flour substitution; $\mathrm{T}_{18}$ - Cookies with $18 \%$ wheat flour substitution; $\mathrm{T}_{24}$ - Cookies with $24 \%$ wheat flour substitution

Upon modification, the creaming process $[3,8]$ was used to make the cookie dough. In an appropriate bowl with a hand mixer, castor sugar and butter were whisked together for $10 \mathrm{~min}$. Subsequently, in the same bowl, the whisked mixture were beat together with eggs and vanilla for 2 minutes briefly. The sifted wheat flour, ground HAp, salt and baking powder were then break technique was used to test all cookie formulations. Quantified parameters were hardness ( $\mathrm{g}$ ) - peak breaking force, fracturability $(\mathrm{mm})$ - mean breaking distance that represents a cookie's tendency to fracture when force is applied and work of breaking force ( $\mathrm{g} \mathrm{s}$ ) - total curve area that represents the total amount of force required to break the sample. 
Measurement employed with the test speed of $3 \mathrm{~mm} / \mathrm{s}$ and the distance between the two bottoms supports was adjusted to $50 \mathrm{~mm}$.

\section{Calcium and Phosphorus Determination}

Calcium and phosphorus were determined in the cookie samples. Briefly, the samples were first dried in an oven at $105^{\circ} \mathrm{C}$ for 24 hours, ground with a porcelain mortar and pestle $6.4 \mathrm{~cm}$ in diameter, then dry-ashed at $550{ }^{\circ} \mathrm{C}$ for 6 hours in a muffle furnace. In $1 \mathrm{M}$ nitric acid $\left(\mathrm{HNO}_{3}\right)$, the ash was subsequently dissolved. The caked, caramel-like mass was then ashed in the same platter again and the second ash dissolved with a few drops of $1 \mathrm{M} \mathrm{HNO}_{3}$.

Adapting from Abdel-Moemin, both calcium and phosphorus is determined by flame atomic absorption spectrometry (Atomic Absorption Spectrophotometer 901, GBC Scientific Equipment Pty Ltd., Melbourne, Victoria, Australia) [8]. Wavelengths of $422.7 \mathrm{~nm}$ for calcium and $715 \mathrm{~nm}$ for phosphorus were used with a $0.2 \mathrm{~nm}$ spectral band width. Reagent blanks was used to correct the instrument readings. Calibration standards established by diluting the high standards of pure commercial metal. The standards were developed from the dissolved $1000 \mathrm{mg} / 1$ standards in $0.1 \mathrm{~N} \mathrm{HNO}_{3}$. A series of working standards was prepared from these standard stock solutions. These standard stock solutions were used to develop a set of working standards. A recovery test for calcium and phosphorus for selected samples was conducted by spiking the analyzed samples with metal standard aliquots and then reanalyzing the samples.

\section{Sensory Evaluation}

Affective testing, or known as hedonic test method, was used to measure the extent of liking or disliking of a product. In this study, the sensory properties of cookies determined using hedonic test method. About 30 untrained panelists were involved in this sensory evaluation. Drinking water was used for the mouth rinsing. The cookies have been evaluated in terms of the colour, odour, flavour, texture and overall acceptability. The scales of rating range from dislike extremely (1) to like extremely (9).

\section{Statistical Analysis}

Results attained in this study are expressed as mean \pm standard deviation of 3 independent replicates. Oneway analysis of variance (ANOVA) and Tukey's Range Test (SPSS software program, Version 25.0, SPSS Inc., Chicago, IL, USA) was used to determine significant difference at the level of $\mathrm{p}$-value $<0.05$.

\section{RESULTS AND DISCUSSION}

\section{Color of Cookies}

The effect of HAp incorporation on colour of cookies is visualized as in Table 2 . The findings indicate that the increasing percentage of HAp used results in generally reduced lightness $\left(\mathrm{L}^{*}\right)$ of cookies. In agreement with Suriya et al., [10], Chauhan et al., [11] and Cheng and Bhat [12], this may be caused by increment in $\mathrm{a}^{*}$ and $b^{*}$ of cookies. As been reported by Cheng and Bhat [12] in their research, yam cookies appeared darker in color due to the reduction in lightness and augmentation in both redness and yellowness value.

Both Maillard reaction caramelization process are responsible for the color of cookies during baking process. In present study, the independent variables were the percentage of HAp utilized to substitute wheat flour. As such, across the level of substitution from $6 \%$ to $24 \%$, percentage of wheat flour used was reduced. Cutting the percentage of wheat flour has resulted in the decreased sugar and protein content in cookies and consequently affected browning reactions. In contrast to Chevallier et al., [13], the whiteness of cookies was negatively proportional to the protein content. This theory suggested, as protein and sugar content were reduced, browning reactions somehow slowed down, thus the cookies appeared less dark. However, in

Table 2: Color Properties of Cookies

\begin{tabular}{cccc}
\hline \multirow{2}{*}{ Formulation } & \multicolumn{3}{c}{ Color Parameter } \\
\cline { 2 - 4 } & $\mathrm{L}^{*}$ & $\mathrm{a}^{*}$ & $\mathrm{~b}^{*}$ \\
$\mathrm{~T} 0$ & $65.24 \pm 1.57^{\mathrm{d}}$ & $3.66 \pm 0.13^{\mathrm{a}}$ & $15.06 \pm 0.677^{\mathrm{a}}$ \\
$\mathrm{T} 6$ & $56.09 \pm 0.51^{\mathrm{c}}$ & $4.09 \pm 0.02^{\mathrm{b}}$ & $16.96 \pm 0.43^{\mathrm{ab}}$ \\
$\mathrm{T} 12$ & $54.89 \pm 0.84^{\mathrm{bc}}$ & $4.33 \pm 0.05^{\mathrm{bc}}$ & $16.64 \pm 0.59^{\mathrm{ab}}$ \\
T18 & $52.00 \pm 1.19^{\mathrm{b}}$ & $4.52 \pm 0.21^{\mathrm{c}}$ & $17.69 \pm 0.84^{\mathrm{b}}$ \\
$\mathrm{T} 24$ & $47.85 \pm 1.27^{\mathrm{a}}$ & $5.10 \pm 0.11^{\mathrm{d}}$ & $22.08 \pm 1.28^{\mathrm{c}}$ \\
\hline${ }^{*}$ Mean with different superscript within the same column are significantly different at $\mathrm{P}<0.05$. & \\
*T $_{0}$ - Control, cookies without wheat flour substitution; $\mathrm{T}_{6}$ - Cookies with $6 \%$ wheat flour substitution; $\mathrm{T}_{12}$ - Cookies with $12 \%$ wheat flour \\
substitution; $\mathrm{T}_{18}$ - Cookies with 18\% wheat flour substitution; $\mathrm{T}_{24}$ - Cookies with 24\% wheat flour substitution
\end{tabular}


present study, the reduction of wheat flour in cookies' formulation contributed to the declination in lightness of cookies. This might be due to the color of HAp which was graying white in color, resulted in darker color perceived.

\section{Texture of Cookies}

The hardness and fracturability of the cookies are shown in Table 3. Substitution of HAp powder in the cookies formulation eventually will result in significant changes to the textural quality of the cookies. Substitution of wheat flour with HAp powder at $24 \%$ level showed the highest hardness. The lowest hardness was noticeable in the control where no HAp powder is mineral form has significantly increased the hardness of cookies. As HAp is naturally dense, it suppressed the expansion of cookies, resulted in more compact cookies, which ultimately necessitated higher energy to break the cookies into pieces during mastication. In line with Nawaz et al., [16], incorporation of fish bone decreased the expansion in fried snacks.

\section{Calcium and Phosphorus Content of Cookies}

As presented in Table 4, cookies formulation in which wheat flour was substituted at 24\% level with HAp exhibited the highest calcium content. Increasing trend was obviously observed as across the level of substitution from $6 \%$ to $24 \%$ level. Conforming to

Table 3: Textural Properties of Cookies

\begin{tabular}{ccc}
\hline Formulation & Texture Parameter & Fracturability \\
\cline { 2 - 3 } & $2101.74 \pm 247.71^{\mathrm{a}}$ & $27.82 \pm 0.23^{\mathrm{a}}$ \\
T0 & $2328.17 \pm 413.89^{\mathrm{b}}$ & $29.60 \pm 0.65^{\mathrm{bc}}$ \\
T12 & $2647.05 \pm 298.32^{\mathrm{c}}$ & $28.36 \pm 0.83^{\mathrm{ab}}$ \\
T18 & $3027.19 \pm 619.30^{\mathrm{d}}$ & $30.94 \pm 0.15^{\mathrm{c}}$ \\
T24 & $3096.68 \pm 631.54^{\mathrm{d}}$ & $29.82 \pm 0.84^{\mathrm{c}}$ \\
\hline *Mean with different superscript within the same column are significantly different at P<0.05. & \\
* $_{0}$ - Control, cookies without wheat flour substitution; $\mathrm{T}_{6}$ - Cookies with 6\% wheat flour substitution; $\mathrm{T}_{12}$ - Cookies with $12 \%$ wheat flour \\
substitution; $\mathrm{T}_{18}$ - Cookies with 18\% wheat flour substitution; $\mathrm{T}_{24}$ - Cookies with 24\% wheat flour substitution
\end{tabular}

being used in the cookies baking.

The findings presented in Table 4.2, indicated that the substitution of wheat flour with HAp has significantly increased the hardness of cookies. The higher percentage of HAp, the harder cookies produced. In this study, HAp was extracted from fish bone by using sintering method or calcination process, where the cleaned bones were heated at a very high temperature $\left(5000{ }^{\circ} \mathrm{C}\right)$. As supported by Hariani and Said [14], by subjecting fish bones to immense temperature, the mechanical properties of extracted HAp were greatly affected, such as the increase of hardness. Calcining in presence of oxygen will remove organic materials, leaving only non-organic material displaying a high degree of crystallinity [15], which ultimately result in increased hardness. Therefore, the substitution of wheat flour with HAp which presents as
Abdul-Moemin [8], calcium content determined was directly proportional to the amount of fish bone incorporated into cookies. Furthermore, fish bone is rich in calcium, phosphate, and carbonate $[17,18]$ where such minerals could be extracted in the form of HAp.

Therefore, the higher amount of HAp added, the higher content of calcium was determined in cookies. Likewise, the phosphorus content in cookies demonstrated increasing trend in parallel with level of substitution and could be observed highest in $\mathrm{T}_{24}$. One might be able to predict the phosphorus (phosphate) content in a sample by knowing the calcium content and divide it with 1.67. The value of 1.67 is the molar ratio of $\mathrm{Ca} / \mathrm{P}$ found in $\mathrm{HAp}$ derived from natural sources [18]. 
Table 4: Textural Properties of Cookies

\begin{tabular}{ccc}
\hline Formulation & Calcium $(\mathrm{g} / 100 \mathrm{~g})$ & Phosphorus $(\mathrm{g} / 100 \mathrm{~g})$ \\
\hline T0 & 0.08 & 0.16 \\
T6 & 1.77 & 1.06 \\
T12 & 3.04 & 1.84 \\
T18 & 4.31 & 2.59 \\
T24 & 6.67 & 4.01 \\
\hline
\end{tabular}

*Mean with different superscript within the same column are significantly different at $\mathrm{P}<0.05$.

$* \mathrm{~T}_{0}$ - Control, cookies without wheat flour substitution; $\mathrm{T}_{6}-$ Cookies with $6 \%$ wheat flour substitution; $\mathrm{T}_{12}-$ Cookies with $12 \%$ wheat flour substitution; $\mathrm{T}_{18}$ - Cookies with $18 \%$ wheat flour substitution; $\mathrm{T}_{24}$ - Cookies with $24 \%$ wheat flour substitution

\section{Sensory Evaluation}

Sensory attributes evaluated by panelists were color, taste, mouthfeel, crispiness and overall acceptability. A 9-point of hedonic scale was used to rate each attribute ranging from score 1 (extremely dislike) to score 9 (extremely like). The samples were served within one week after production. The mean scores of each attribute were presented in the Table 5. 30 untrained panelists consisted of students and staff of University College of Technology Sarawak involved in this sensory evaluation of cookies. treated samples. This parameter exhibited declining trend as the percentage of HAp used was increased.

It implies that the addition of HAp into cookies formulation had significantly reduce the taste acceptability. Based on the study conducted by Tyagi $e t$ al., [19], the taste of cookies is affected by the ingredients used. It indicates that, in spite of the nature of HAp which presents in the form of tasteless powder, it somehow gives unpleasant taste to the cookies. Chaudari and Fanion [20] suggested that the incorporating in demand nutrients into food may influence sensory characteristics including taste,

Table 5: Sensory Acceptability of Cookies

\begin{tabular}{cccccc}
\hline \multirow{2}{*}{ Sensory Attribute } & \multicolumn{5}{c}{ Formulation } \\
\cline { 2 - 5 } & $\mathrm{T}_{0}$ & $\mathrm{~T}_{6}$ & $\mathrm{~T}_{12}$ & $\mathrm{~T}_{18}$ & $\mathrm{~T}_{24}$ \\
\hline Color & $8.77 \pm 0.73^{\mathrm{a}}$ & $8.27 \pm 0.64^{\mathrm{a}}$ & $5.57 \pm 0.97^{\mathrm{b}}$ & $4.37 \pm 0.85^{\mathrm{b}}$ & $2.77 \pm 0.43^{\mathrm{c}}$ \\
Taste & $8.93 \pm 0.25^{\mathrm{a}}$ & $7.53 \pm 0.51^{\mathrm{ab}}$ & $6.43 \pm 0.50^{\mathrm{b}}$ & $5.17 \pm 0.59^{\mathrm{bc}}$ & $3.43 \pm 0.50^{\mathrm{c}}$ \\
Mouthfeel & $9.00 \pm 0.00^{\mathrm{a}}$ & $7.53 \pm 0.51^{\mathrm{b}}$ & $5.13 \pm 0.35^{\mathrm{c}}$ & $3.63 \pm 0.67^{\mathrm{d}}$ & $1.87 \pm 0.35^{\mathrm{e}}$ \\
Crispiness & $8.80 \pm 0.41^{\mathrm{a}}$ & $7.43 \pm 0.50^{\mathrm{b}}$ & $5.60 \pm 0.50^{\mathrm{c}}$ & $4.30 \pm 0.47^{\mathrm{c}}$ & $2.07 \pm 0.79^{\mathrm{d}}$ \\
Overall Acceptability & $8.50 \pm 0.51^{\mathrm{a}}$ & $7.63 \pm 0.49^{\mathrm{b}}$ & $5.63 \pm 0.49^{\mathrm{b}}$ & $4.10 \pm 0.40^{\mathrm{c}}$ & $2.17 \pm 0.70^{\mathrm{d}}$
\end{tabular}

*Mean with different superscript within the same row are significantly different at $\mathrm{P}<0.05$.

$* \mathrm{~T}_{0}$ - Control, cookies without wheat flour substitution; $\mathrm{T}_{6}-$ Cookies with $6 \%$ wheat flour substitution; $\mathrm{T}_{12}-$ Cookies with $12 \%$ wheat flour substitution; $\mathrm{T}_{18}$ - Cookies with $18 \%$ wheat flour substitution; $\mathrm{T}_{24}$ - Cookies with $24 \%$ wheat flour substitution

Referring to the Table 5, the effect of HAp incorporated on color acceptability of cookies demonstrated declining rating as across the level of substitution from $6 \%$ to $24 \%$. It indicates that lighter color of cookies was more preferable among panelists.

This finding is supported by the result from color analysis (Table 2) where the lightness $\mathrm{L}^{*}$ of cookies was negatively correlated with percentage of HAp used. Likely, Abdul-Moemin [8] suggested reduced color acceptability along with augmentation in percentage of Nile tilapia bones in cookies.

As for the taste acceptability of cookies, there were significant difference between control sample and appearance, texture and other attributes as these eventually constitute perceived product quality.

The mouthfeel acceptability of cookies was indirectly proportional to the percentage of HAp used. The addition of HAp into cookies formulation significantly reduced mouthfeel acceptability. This finding could be justified with the fact that HAp present in the form of crystalline grains [21]. This physical characteristic of HAp resulted in distinctive sandiness in cookies. The results is supported by Engelen et al., [22], suggesting that the addition of particles with larger size increased the sensation of roughness attributes in vanilla custard dessert, perceived as sandiness or grittiness. 
Table 5 also represents the negative correlation between crispiness acceptability and percentage of HAp used. According to Pereira et al., [23], the crispiness of the cookies is directly correlated to the hardness of the cookies. Nevertheless, panelists had rated control sample as the best for its crispiness. It indicates, hardness of cookies over $2101 \mathrm{~g}$ yielded unacceptable crispiness for panelists.

Control sample recorded the highest score for overall acceptability. Generally, overall acceptability exhibited decreasing trend as the percentage of HAp added increased. According to Stone et al., [24], overall acceptability necessitates the panelists rate the product as a whole without direction to any sensory aspects that are considered important. However, in addition to the significant differences observed, the declined mouthfeel and crispiness acceptability might also lessen the overall acceptability. According to Devereux et al., [25], Texture is one of the key attributes of food quality, where lower texture scores may lessen overall acceptability.

\section{CONCLUSION}

Conclusively, cookies fortified with calcium by utilizing HAp extracted from Decapterus maacrosoma bones was successfully produced. In terms of colour analysis, as across level of substitution from $6 \%$ to $24 \%, \mathrm{~L}^{*}$ decreased along with the increased $\mathrm{a}^{*}$ and $\mathrm{b}^{*}$. The hardness and fracturability of treated cookies demonstrated increasing trend as the amount of HAp used was escalated, ranging from $2328-3096 \mathrm{~g}$ for the former and $29.6-30.94 \mathrm{~mm}$ for the latter. Similar trend was observed in calcium content. As expected, both calcium and phosphorus content was found highest in sample $\mathrm{T}_{24}$ as this sample had highest percentage of HAp. Meanwhile, as across the substitution level from $6 \%$ to $24 \%$, the results from sensory evaluation has demonstrated declined trend in all sensory attributes analyzed; color, taste, mouthfeel, crispiness and overall acceptability.

It is recommended to discover other methods of comminution to reduce the particle size of HAp into nano-sized particles to enhance sensory qualities of cookies such as texture and mouthfeel characteristics. Besides, it is highly suggested to determine microbiological properties of the cookies incorporated with HAp from Decapterus macrosoma bones as well as the absorption rate of calcium in human through bioavailability study.

\section{ACKNOWLEDGEMENT}

This project is supported under University College of Technology Sarawak internal research grant (UCTS/RESEARCH/<4/2018/04>(01)

\section{REFERENCES}

[1] Gandhi, A. P., Kotwaliwale, N., Kawalkar, J., Srivastav, D. C., Parihar, V. S., \& Nadh, P. R. (2001). Effect of incorporation of defatted soyflour on the quality of sweet biscuits.

[2] Jemziya, M. B. F., \& Mehentran, T. (2015). Quality characteristics and sensory evaluation of cookies produced from composite blends of sweet potato (Ipomoea batatas L.) and wheat (Triticum aestivum L.) flour.

[3] Saba, N.H. 1997. Culinary is Science and Art. Cairo, Egypt : DarEl-Maaref.

[4] Agrahar-Murugkar, D., Dwivedi, S., Dixit-Bajpai, P., \& Kumar, M. (2018). Effect of natural fortification with calcium and protein rich ingredients on texture, nutritional quality and sensory acceptance of cookies. Nutrition \& Food Science, 48(5), 807-818.

[5] Mohsin, A. K. M., \& Ambak, M. A. (1996). Marine fishes and fisheries of Malaysia and neighbouring countries.

[6] Quiñones, R. S. (2015). Development of CalciumEnriched Gluten-Free Cookies. Journal of Agriculture and Technology Management, 10-10.

[7] Gomes, D. S., Santos, A. M. C., Neves, G. A., \& Menezes, R. R. (2019). A brief review on hydroxyapatite production and use in biomedicine. Cerâmica, 65(374), 282-302.

[8] Abdel-Moemin, A. R. (2015). Healthy cookies from cooked fish bones. Food bioscience, 12, 114121.

[9] Budžaki, S., Koceva Komlenić, D., Lukinac Čačić, J., Čačić, F., Jukić, M., \& Kožul, Ž. (2014). Influence of cookies composition on temperature profiles and qualitative parameters during baking. Croatian journal of food science and technology, 6(2), 72-78.

[10] Suriya, M., Rajput, R., Reddy, C. K., Haripriya, S., \& Bashir, M. (2017). Functional and physicochemical characteristics of cookies prepared from Amorphophallus paeoniifolius flour. Journal of food science and technology, 54(7), 2156-2165.

[11] Chauhan, A., Saxena, D. C., \& Singh, S. (2015). Total dietary fibre and antioxidant activity of gluten free cookies made from raw and germinated amaranth (Amaranthus spp.) flour. LWT-Food Science and Technology, 63(2), 939945.

[12]Cheng, Y. F., \& Bhat, R. (2016). Functional, physicochemical and sensory properties of novel cookies produced by utilizing underutilized jering (Pithecellobium jiringa Jack.) legume flour. Food bioscience, 14, 54-61. 
[13] Chevallier, S., Colonna, P., Buléon, A., \& Della Valle, G. (2000). Physicochemical behaviors of sugars, lipids, and gluten in short dough and biscuit. Journal of Agricultural and Food Chemistry, 48(4), 1322-1326.

[14] Hariani, P. L., \& Said, M. (2019, April). Effect of sintering on the mechanical properties of hydroxyapatite from fish bone (Pangasius Hypophthalmus). In IOP Conference Series: Materials Science and Engineering (Vol. 509, No. 1, p. 012109). IOP Publishing.

[15] Soares, M. M. N., Poggiali, F. S., Bezerra, A. C. S., Figueiredo, R. B., Aguilar, M. T. P., \& Cetlin, P. R. (2014). The effect of calcination conditions on the physical and chemical characteristics of sugar cane bagasse ash. Rem: Revista Escola de Minas, 67(1), 33-39.

[16] Nawaz, A., Xiong, Z., Xiong, H., Chen, L., Wang, P. K., Ahmad, Hu, C., Irshad, S., \& Ali, S. W. (2019). The effects of fish meat and fish bone addition on nutritional value, texture and microstructure of optimised fried snacks. International Journal of Food Science \& Technology, 54(4), 1045-1053.

[17] Akram, M., Ahmed, R., Shakir, I., Ibrahim, W. A. W., \& Hussain, R. (2014). Extracting hydroxyapatite and its precursors from natural resources. Journal of Materials Science, 49(4), 1461-1475.

[18] Pu'ad, N. M., Koshy, P., Abdullah, H. Z., Idris, M. I., \& Lee, T. C. (2019). Syntheses of hydroxyapatite from natural sources. Heliyon, 5(5), e01588.

[19] Tyagi, S. K., Manikantan, M. R., Oberoi, H. S., \& Kaur, G. (2007). Effect of mustard flour incorporation on nutritional, textural and organoleptic characteristics of biscuits. Journal of Food Engineering, 80(4), 1043-1050.

[20] Chaudhari, R., \& Fanion, M. (2008). Technical aspects of micronutrient addition to foods. In Food Fortification and Supplementation (pp. 108-125). Woodhead Publishing.

[21] Boutinguiza, M., Pou, J., Comesaña, R., Lusquiños, F., De Carlos, A., \& León, B. (2012). Biological hydroxyapatite obtained from fish bones. Materials Science and Engineering: C, 32(3), 478-486.

[22] Engelen, L., de Wijk, R. A., van der Bilt, A., Prinz, J. F., Janssen, A. M., \& Bosman, F. (2005). Relating particles and texture perception. Physiology \& behavior, 86(1-2), 111-117.

[23] Pereira, D., Correia, P. M., \& Guiné, R. P. (2013). Analysis of the physical-chemical and sensorial properties of Maria type cookies. Acta Chimica Slovaca, 6(2), 269-280.

[24] Stone, H., Bleibaum, R. N., \& Thomas, H. A. (2012). Sensory evaluation practices. Academic press.

[25] Devereux, H. M., Jones, G. P., McCormack, L., \& Hunter, W. C. (2003). Consumer acceptability of low fat foods containing inulin and oligofructose. Journal of Food Science, 68(5), 1850-1854. 